\title{
ФИЗИКА
}

УДК 53.082 .534

\section{Спектральный показатель поглощения света желтым веществом и его изменчивость в континентальном водоеме}

О.Б. Акулова, В.И. Букатый, К.П. Попов

Институт водных и экологических проблем СО РАН (Барнаул, Россия)

\section{Variation of Light Absorption by Yellow Substance in Surface Layer of Continental Reservoir} O.B. Akulova, V.I. Bukaty, K.P. Popov

Institute for Water and Environmental Problems SB RAS (Barnaul, Russia)

\begin{abstract}
В статье приведены экспериментальные данные по изменению показателя поглощения света желтым веществом в поверхностном слое Новосибирского водохранилища, полученные в августе 2017 г. в ходе экспедиционных гидрологических, гидробиологических и гидрохимических исследований. Рассчитанные значения показателя поглощения света желтым веществом в спектральном диапазоне 400-800 нм за исследуемый период находились в диапазоне от 1,0 до 9,7 $\mathrm{m}^{-1}$, показателя ослабления света - от 2,0 до 14,0 м $^{-1}$. Измерены концентрации компонентов воды: хлорофилла «а», органо-минеральной взвеси, желтого вещества. Содержание хлорофилла в воде изменялось в пределах 7,0-39,3 мг/м³ среднее значение массовой концентрации частиц взвеси составило 14,30 мг/л. Концентрация желтого вещества на водохранилище, определяемая оптическим методом по измеренному показателю поглощения света желтым веществом на длине волны $\lambda=450$ нм, варьировала в пределах 17,430,8 г/м $\mathbf{m}^{3}$. Для нахождения коэффициентов экспоненциального наклона кривой спектрального показателя поглощения желтым веществом в воде Новосибирского водохранилища построены соответствующие аппроксимационные зависимости. Сделана оценка спектрального вклада основных оптически активных компонентов воды (желтого вещества, взвеси, хлорофилла, чистой воды) в показатель ослабления света для поверхностного слоя водоема. Выявлено, что во всех точках водохранилища максимальный вклад вносит желтое вещество.
\end{abstract}

The paper presents experimental data on variation of light absorption by yellow substance in the surface layer of the Novosibirsk reservoir, obtained in August 2017 during hydrological, hydrobiological and hydrochemical investigations. The calculated light absorption index by yellow substance in the spectral range of $400-800 \mathrm{~nm}$ varied from 1.0 to $9.7 \mathrm{~m}^{-1}$, the light attenuation index from 2.0 to $14.0 \mathrm{~m}^{-1}$. Concentration of chlorophyll "a", organic-mineral suspension, and yellow substance was measured. Chlorophyll content in water changed within $7.0-39.3 \mathrm{mg} / \mathrm{m}^{3}$, the average mass concentration of suspended particles made up $14.30 \mathrm{mg} / \mathrm{l}$. Concentration of yellow substance in the reservoir, evaluated by optical method using the rate of light absorption by yellow substance at the wavelength $\lambda=450 \mathrm{~nm}$, varied from 17.4 to $30.8 \mathrm{~g} / \mathrm{m}^{3}$. To estimate the exponential slope coefficients of the spectral absorption curve of the yellow substance in the Novosibirsk reservoir, the appropriate approximation dependences are constructed. The assessment of spectral contribution of major optically active water components (yellow substance, suspension, chlorophyll, clean water) to the light attenuation is carried out for the surface layer of the reservoir. It is revealed that the most significant contribution at all sites of the reservoir is made by yellow substance.

^Работа выполнена в рамках госбюджетного проекта ИВЭП СО РАН № 0383-2016-0002 «Изучение гидрологических и гидрофизических процессов в водных объектах и на водосборах Сибири и их математическое моделирование для стратегии водопользования и охраны водных ресурсов». 
Ключевые слова: спектральная прозрачность воды, показатель ослабления света, показатель поглощения света, желтое вещество, физическая модель.
Key words: spectral transparency of water, coefficients of light attenuation, coefficients of light absorption, yellow substance, physical. model.

\section{DOI 10.14258/izvasu(2018)4-01}

Введение. Наиболее важные гидрооптические характеристики как индикаторы экологического состояния водных экосистем - спектральные показатели ослабления $\varepsilon(\lambda)$, поглощения $\kappa(\lambda)$ и рассеяния $\sigma(\lambda)$ света, а также относительная прозрачность $Z_{6}$ по белому диску Секки. Изучение гидрооптических характеристик вносит определенный вклад в формирование представлений о гидрофизических условиях функционирования водных экосистем разных типов (океанов, морей, рек, озер, водохранилищ) [1-5].

Для решения ряда вопросов, связанных с проблемой распространения оптического излучения в природных водных объектах, важно знать величины спектрального вклада основных оптически активных компонентов среды в общее ослабление света, что является актуальной задачей. Однако основная сложность заключается в чрезвычайном разнообразии и пространственно-временной изменчивости конкретного компонента водоемов (чистая вода, ор- гано-минеральная взвесь, желтое вещество, хлорофилл), определяющего спектральный вклад в показатель ослабления света.

Настоящая работа посвящена изучению пространственной изменчивости показателя поглощения света желтым веществом $\kappa_{ж в}(\lambda)$ и концентрации желтого вещества как наиболее оптически активной компоненты, а также расчетам спектральных вкладов в суммарный показатель ослабления света на примере Новосибирского водохранилища.

Материалы и методы проводимого исследования. Новосибирское водохранилище - единственный крупный в бассейне р. Оби искусственный водоем многоцелевого назначения. По гидрологическому режиму и морфометрическим характеристикам водохранилище является типично равнинным водоемом и делится на три основные части: нижнюю - озеровидную, среднюю - суженную и верхнюю - расширенную (схема) [6].

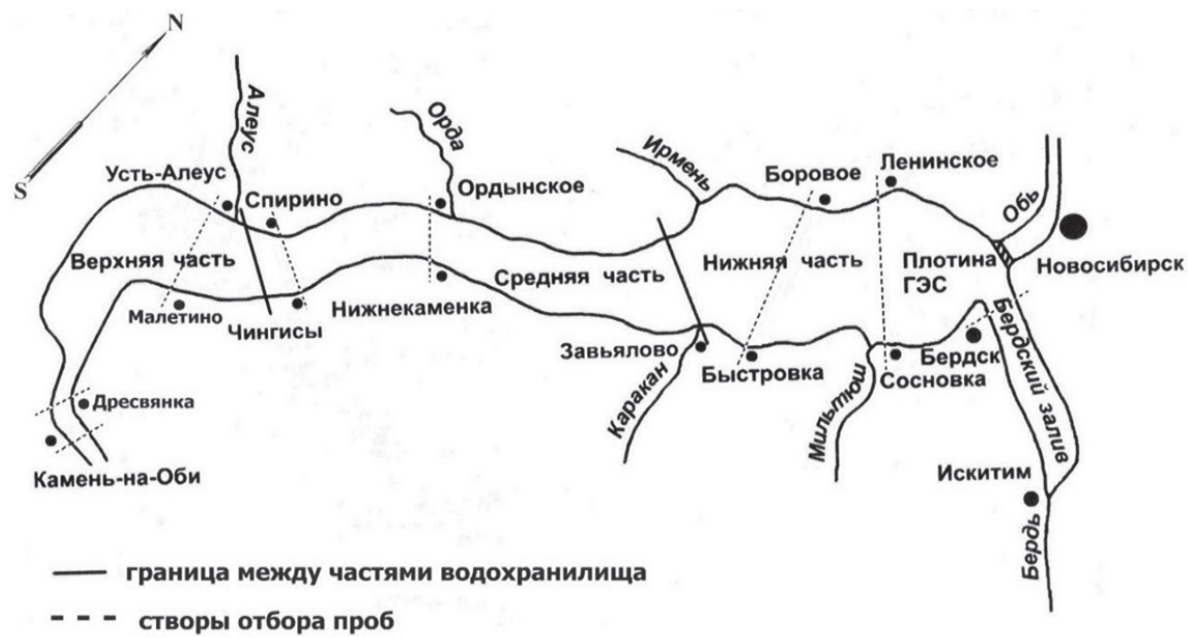

Схема Новосибирского водохранилища

В период с 14 по 16 августа 2017 г. в ходе летних экспедиционных работ на Новосибирском водохранилище отобрали пробы воды (всего 17 проб) с поверхностного слоя исследуемого объекта. Точки отбора проб и их координаты представлены в таблице 1. Провели 408 измерений спектральной прозрачности воды на спектрофотометре до и после фильтрации проб. Обработали 85 микрофотографий с общим количеством частиц 2332 шт.

Для определения спектральной прозрачности воды применили спектрофотометрический ме- тод, в основу которого положен принцип измерения отношения двух световых потоков, проходящих через объемы с исследуемой и эталонной средами. В качестве последней использовали дважды очищенную дистиллированную воду. Спектральные измерения провели в лаборатории с помощью спектрофотометра типа ПЭ-5400УФ. Затем рассчитали первичную гидрооптическую характеристику спектральный показатель ослабления света $\varepsilon(\lambda)$ по формуле $\varepsilon(\lambda)=(1 / L) \cdot \ln (1 / T)$, где $L-$ длина кюветы, $T=I / I_{0}-$ прозрачность в относительных еди- 
Таблица 1

Точки отбора проб и их координаты со значениями показателя поглощения света желтым веществом при $\lambda=450$ нм и концентрации желтого вещества

\begin{tabular}{|c|c|c|c|}
\hline Точки (название) & Координаты & 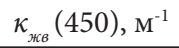 & $C_{\dddot{H} B}, \Gamma / \mathrm{M}^{3}$ \\
\hline Т. 2.2 (Дресвянка, середина) & $\begin{array}{l}53,5225957 \mathrm{~N} \\
81,1943302 \mathrm{E}\end{array}$ & 4,8 & 22,8 \\
\hline Т. 3.2 (Малетино, середина) & $\begin{array}{l}54,0253884 \mathrm{~N} \\
81,2435273 \mathrm{E}\end{array}$ & 4,1 & 19,4 \\
\hline Т. 4.2 (Спирино, середина) & $\begin{array}{l}54,0738719 \mathrm{~N} \\
81,3344964 \mathrm{E}\end{array}$ & 5,3 & 25,3 \\
\hline Т. 5.1 (Ордынское -Нижнекаменка, левый берег) & $\begin{array}{l}54,2112316 \mathrm{~N} \\
81,5434117 \mathrm{E}\end{array}$ & 6,0 & 28,0 \\
\hline Т. 5.2 (Ордынское -Нижнекаменка, середина) & $\begin{array}{l}54,2021050 \mathrm{~N} \\
81,5423840 \mathrm{E}\end{array}$ & 3,7 & 17,4 \\
\hline Т. 5.3 (Ордынское -Нижнекаменка, правый берег) & $\begin{array}{l}54,1926605 \mathrm{~N} \\
81,5436392 \mathrm{E}\end{array}$ & 4,3 & 20,4 \\
\hline Т. 6.1 (Боровое - Быстровка, левый берег) & $\begin{array}{l}54,3938851 \mathrm{~N} \\
82,3436739 \mathrm{E}\end{array}$ & 4,7 & 22,5 \\
\hline Т. 6.2 (Боровое - Быстровка, середина) & $\begin{array}{l}54,3621449 \mathrm{~N} \\
82,3425392 \mathrm{E}\end{array}$ & 4,6 & 21,7 \\
\hline Т. 6.3 (Боровое - Быстровка, правый берег) & $\begin{array}{l}54,3352643 \mathrm{~N} \\
82,3308600 \mathrm{E}\end{array}$ & 5,7 & 27,2 \\
\hline Т. 7.1 (Ленинское - Сосновка, левый берег) & $\begin{array}{l}54,4752854 \mathrm{~N} \\
82,5136209 \mathrm{E}\end{array}$ & 5,0 & 23,2 \\
\hline Т. 7.2 (Ленинское - Сосновка, середина) & $\begin{array}{l}54,4534600 \mathrm{~N} \\
82,5209088 \mathrm{E}\end{array}$ & 5,4 & 25,5 \\
\hline Т. 7.3 (Ленинское - Сосновка, правый берег) & $\begin{array}{l}54,4108884 \mathrm{~N} \\
82,5331697 \mathrm{E}\end{array}$ & 6,0 & 28,5 \\
\hline Т. 9.2 (Бердский залив, Речкуновка) & $\begin{array}{l}54,4735297 \mathrm{~N} \\
83,0420651 \mathrm{E}\end{array}$ & 6,5 & 30,8 \\
\hline Т. 10.2 (Верхний бьеф, у плотины ГЭС) & $\begin{array}{l}54,4954354 \mathrm{~N} \\
82,5811518 \mathrm{E}\end{array}$ & 4,2 & 19,7 \\
\hline Т. 31.1 (Камень-на-Оби, левый берег) & $\begin{array}{l}53,4646657 \mathrm{~N} \\
81,2411675 \mathrm{E}\end{array}$ & 5,7 & 27,0 \\
\hline Т. 31.2 (Камень-на-Оби, середина) & $\begin{array}{l}53,4629932 \mathrm{~N} \\
81,2320987 \mathrm{E}\end{array}$ & 5,0 & 23,7 \\
\hline Т. 31.3 (Камень-на-Оби, правый берег) & $\begin{array}{l}53,4700535 \mathrm{~N} \\
81,2356184 \mathrm{E} \\
\end{array}$ & 4,5 & 21,5 \\
\hline
\end{tabular}

ницах, $I, I_{0}-$ интенсивности прошедшего и падающего света, соответственно, $\lambda$ - длина волны света. Абсолютная погрешность величины $\varepsilon(\lambda)$ обусловлена погрешностью измерения коэффициента пропускания $(T=0,5 \%)$ с помощью спектрофотометра и погрешностью определения длины кюветы $(L=10$ мм). Максимальная абсолютная погрешность измерений показателя ослабления света составила $0,5 \mathrm{M}^{-1}$. Показатель поглощения света желтым веществом $\kappa_{ж в}(\lambda)$ определили после измерения спектральной прозрачности исследуемой воды, очищенной от взвеси фильтрованием с использованием мембранных фильтров «Владипор» типа МФАС-ОС-1 с диаметром пор 0,22 мкм. Концентрацию желтого вещества $C_{ж в}$ определили из выражения, приведенного в работе [7] $C_{ж в}=\kappa_{ж в}(450) / \kappa_{\text {уджв }}(450)$, где $\kappa_{\text {уджв }}(\lambda)-$ удельный показатель поглощения света желтым веществом из работы [8] при $\lambda=450$ нм. Концентрацию хлорофилла «а» в ацетоновых экстрактах водорослей фитопланктона определили стандартным спектрофотометрическим методом согласно [9]. Количество и размеры частиц взвеси определили с помощью счетной камеры Нажотта объемом 0,05 мл с использованием светового микроскопа Nikon Eclipse 80i. Относительный спектральный вклад компонентов воды в $\varepsilon(\lambda)$ в поверхностном слое исследуемого водохранилища рассчитали с использованием спектральной физической модели ослабления света, предложенной О.В. Копелевичем в работе [5], имеющей вид $\varepsilon(\lambda)=\kappa_{x л}(\lambda)+\kappa_{\text {жв }}(\lambda)+\sigma_{\text {мол }}(\lambda)+\sigma_{\text {вз }}(\lambda)+\kappa_{\text {ив }}(\lambda)$, где $\kappa_{x л}(\lambda)$ и $\kappa_{ж в}(\lambda)-$ показатели поглощения хлорофиллом и желтым веществом, соответственно, $\sigma_{\text {мол }}(\lambda)-$ показатель молекулярного рассеяния чистой водой, $\sigma_{в 3}(\lambda)$ - показатель рассеяния органо-минеральной взвесью, $\kappa_{\text {чв }}(\lambda)-$ показатель поглощения чистой водой. Показатель поглощения хлорофиллом рассчитали по формуле $\kappa_{x л}(\lambda)=\kappa_{y \partial . x л}(\lambda) \cdot C_{x л}[5]$.

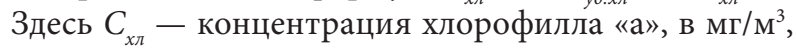


$\kappa_{\text {уд.хл }}(\lambda)$ - удельный показатель поглощения хлорофиллом, в м ${ }^{2} /$ мг. Для расчетов $\kappa_{\text {ия }}(\lambda)$ использовали табличные данные $[10,11]$, а для $\sigma_{\text {мол }}(\lambda)$ - взяли из работы [5]. Спектральный показатель рассеяния взвесью $\sigma_{63}(\lambda)$ определили по формуле $\sigma_{\theta 3}(\lambda)=\varepsilon(\lambda)-\left[\kappa_{x л}(\lambda)+\right.$ $\left.\kappa_{\text {жв }}(\lambda)+\sigma_{\text {мол }}(\lambda)+\kappa_{\text {чв }}(\lambda)\right]$.

Полученные результаты и их обсуждение. Значения спектрального показателя ослабления света $\varepsilon(\lambda)$ при $\lambda=430$ нм в поверхностном слое Новосибирского водохранилища находились в диапазоне от 6,5 до 11,2 $\mathrm{M}^{-1}$, показателя поглощения света

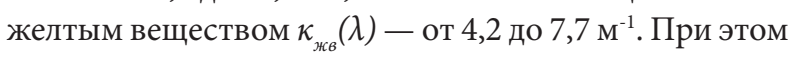
среднее значение за исследуемый период для $\varepsilon(\lambda)$ составило 8,3 $\mathrm{M}^{-1}$, для $\kappa_{\text {ж⿻ }}(\lambda)-5,7 \mathrm{~m}^{-1}$ (величины $\varepsilon(\lambda)$ и $\kappa_{ж в}(\lambda)$ рассчитаны при натуральном основании логарифма). Концентрация основного фотосинтетического пигмента хлорофилла «а» - Chl ${ } a^{\prime \prime}$ является интегральным показателем для оценки уровня развития водорослей планктона и перифитона, трофического состояния водоема и качества воды. За период исследований содержание $C h l_{\text {"a" }}$ в воде изменялось в пре-

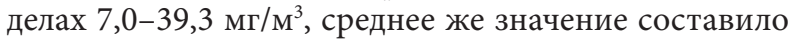
$19,6 \mathrm{Mг} / \mathrm{M}^{3}$. В результате расчетов Новосибирское водохранилище соответствует эвтрофному типу водоемов с элементами мезотрофии. Оценка трофического статуса основана на индексе Карлсона (Trophic State Index) [12] и согласуется с классификацией [13], в которой в качестве дополнительного параметра выбран спектральный показатель ослабления света.

Для Новосибирского водохранилища построены эмпирические аппроксимационные зависимости между значениями натурального логарифма спектрального показателя поглощения света желтым веществом $\ln \kappa_{ж в}(\lambda)$ и длиной волны света $\lambda$. Для всех исследуемых точек водохранилища коэффициент детерминации $R^{2}$ находился в диапазоне 0,91-0,97, при этом коэффициент экспоненциального наклона $\mu$, харак- теризующий крутизну кривой $\kappa_{ж в}(\lambda)$ [14], варьировал в пределах 0,002-0,005 нм$^{-1}$.

В таблице 1 представлены результаты измерений показателя поглощения света желтым веществом $\kappa_{\text {жв }}(\lambda)$ и расчетов концентрации желтого вещества $C_{ж в}$ в поверхностном слое исследуемого водохранилища.

Рассчитан спектральный вклад основных компонентов озерной воды в спектральный показатель ослабления света для 13 точек поверхностного слоя Новосибирского водохранилища. В результате получено, что желтое вещество (ЖВ) дает максимальный вклад в показатель ослабления света при $\lambda=430$ нм в районе Бердского залива (Т.9.2) и составляет $85,4 \%$, в остальных точках вклад ЖВ - более $50 \%$. При $\lambda=550$ нм вклад желтого вещества на Новосибирском водохранилище находится в пределах от 49,6\% (Т. 4.2 - Спирино, середина) до 72,2\% (Т. 7.3 - Ленинское - Сосновка, правый берег). При $\lambda=670$ нм максимальное значение вклада ЖВ зафиксировано на левом берегу г. Каменьна-Оби в Т. $31.1-65,2 \%$. Взвесь дает максимальный вклад в показатель ослабления при $\lambda=430$ нм в точке Т. 6.1 (Боровое - Быстровка, левый берег) и составляет $35,1 \%$. Вклад взвеси возрастает до $45,6 \%$ (Т. 4.2) при $\lambda=550$ нм. При $\lambda=670$ нм вклад взвеси на Новосибирском водохранилище варьирует в пределах от $0,4 \%$ (Т. 31.1 ) до 33,3\% (Т. $5.2-$ Ордынское - Нижнекаменка, середина). Чистая вода вносит несущественный вклад в ослабление света при $\lambda=430$ нм на всех точках и составляет не более $0,1 \%$, но резко увеличивается в длинноволновой области: до 18,0\% при $\lambda=670$ нм. Вклад хлорофилла при $\lambda=430$ нм находится в диапазоне от 5,8\% (Т. $5.1-$ Ордынское - Нижнекаменка, левый берег) до 35,2\% (Т. 3.2 - Малетино, середина), при $\lambda=550$ нм от $0,9 \%$ (Т. 5.1 ) до $3,6 \%$ на левом и правом берегах

Таблица 2

Размер и концентрации частиц взвеси

\begin{tabular}{|c|c|c|c|}
\hline Точки отбора проб & $\begin{array}{c}\text { Средний радиус частиц, } \\
\text { мкм }\end{array}$ & $\begin{array}{c}\text { Средняя счетная концентрация, } \\
10^{6} \mathrm{~cm}^{-3}\end{array}$ & $\begin{array}{c}\text { Массовая концентрация, } \\
\text { мг/л }\end{array}$ \\
\hline T. 2.2 & 1,8 & 2,3 & 31,2 \\
T. 3.2 & 1,5 & 1,4 & 33,5 \\
T. 4.2 & 1,2 & 1,0 & 3,6 \\
T. 5.1 & 0,9 & 2,7 & 2.9 \\
T. 5.2 & 1,0 & 2,0 & 9,6 \\
T. 5.3 & 1,3 & 0,8 & 4,5 \\
T. 6.1 & 1,0 & 1,2 & 4,9 \\
T. 6.2 & 1,7 & 1,8 & 2,6 \\
T. 6.3 & 1,1 & 1,3 & 7,6 \\
T. 7.1 & 1,6 & 2,2 & 8,9 \\
T. 7.2 & 1,6 & 1,6 & 9,2 \\
T. 7.3 & 1,8 & 2,8 & 5,8 \\
T. 9.2 & 1,8 & 1,5 & 13,6 \\
T. 10.2 & 1,7 & 1,7 & 35,5 \\
T. 31.1 & 1,8 & 1,5 & 25,1 \\
T. 31.2 & 1,7 & 1,7 & 29,5 \\
T. 31.3 & 1,5 & 1,3 & \\
\hline
\end{tabular}


г. Камень-на-Оби (Т. 31.1 и Т. 31.3). При $\lambda=670$ нм максимальное значение вклада хлорофилла зафиксировано в Малетино (Т. 3.2) - 32,8\%. Молекулярное рассеяние света чистой водой в исследуемом спектральном интервале 400-800 нм не вносит ощутимый вклад и составляет около $0,1 \%$.

В таблице 2 представлены результаты расчетов размерного состава и концентраций частиц водной взвеси в исследуемом водном объекте. Объем каждой профильтрованной пробы составил 200 мл.

В результате расчетов размерного состава и концентраций частиц водной взвеси в 17 точках отбора проб получено, что средневзвешенный радиус частиц в поверхностном слое Новосибирского водохранилища составил 1,4 мкм, среднее значение счетной концентрации частиц взвеси составило порядка $1,7 \cdot 10^{6} \mathrm{~cm}^{-3}$, массовой концентрации - 14,30 мг/л.

Заключение. В работе по измерениям коэффициента пропускания в диапазоне длин волн от 400 до 800 нм (с шагом 30 нм) в пробах воды Новосибирского водохранилища, пропущенных через фильтр с диаметром пор 0,22 мкм, опреде- лен спектральный показатель поглощения света желтым веществом. Проанализирована пространственная изменчивость концентрации желтого вещества, определяемой оптическим методом, в поверхностном слое Новосибирского водохранилища. Вычислен коэффициент экспоненциального наклона кривой спектрального показателя поглощения желтым веществом в воде исследуемого водоема. Оценен спектральный вклад компонентов воды в показатель ослабления света для поверхностного слоя водохранилища в различных точках отбора проб. Рассчитаны массовые концентрации взвешенного в воде вещества по акватории Новосибирского водохранилища, а также счетные концентрации частиц взвеси и их размеры.

Благодарности. Выражаем благодарность научному сотруднику лаборатории водной экологии ИВЭП СО РАН А.В. Котовщикову за отбор проб воды и предоставленные данные измерений концентрации хлорофилла «а», аспиранту лаборатории гидрологии и геоинформатики ИВЭП СО РАН М.Е. Литвиху за помощь в обработке частиц взвеси.

\section{Библиографический список}

1. Чурилова Т.Я., Суслин В.В., Рылькова О.А. Параметризация поглощения света основными оптически активными компонентами в Чёрном море // Экологическая безопасность прибрежной и шельфовой зон и комплексное использование ресурсов шельфа. - Севастополь, 2008. — № 16.

2. Ефимова В.Т., Моисеева Н.А., Чурилова Т.Я., Кривенко О.В. Поглощение света оптически активными компонентами среды в зоне фотосинтеза глубоководной части Чёрного моря (сентябрь 2015 года) // Экологическая безопасность прибрежной и шельфовой зон моря. - Севастополь, 2016. — № 4.

3. Маньковский В.И. Основы оптики океана : методическое пособие. - Севастополь, 1996.

4. Шифрин К.С. Введение в оптику океана. - Л., 1983.

5. Оптика океана. Т. 1. Физическая оптика океана / под ред. А.С. Монина. - М., 1983.

6. Многолетняя динамика водно-экологического режима Новосибирского водохранилища / В.М. Савкин [и др.]; отв. ред. О.Ф. Васильев. - Новосибирск, 2014.

7. Маньковский В.И. Желтое вещество в поверхностных водах восточной части Тропической Атлантики // Морской гидрофизический журнал. - 2015. - № 3.

8. Nyquist G. Investigation of some optical properties of sea water with special reference to lignin sulfonates and humic substances // PhD Thesis, Dept. Analytical and Marine Chemistry, Göteborg University, Göteborg, Sweden, 1979.

9. ГОСТ 17.1.4.02-90. Государственный контроль качества воды. Методика спектрофотометрического определения хлорофилла а. - М., 2003.

10. Pope R.M., Fry E.S. Absorption spectrum (380-700 nm) of pure water. II. Integrating cavity measurements // Applied Optics. 1997. - Vol. 36. — № 33.

11. Левин И.М. Малопараметрические модели первичных оптических характеристик морской воды // Фундаментальная и прикладная гидрофизика. - 2014. - Т. 7. № 3 .

12. Carlson R.E. A trophic state index for lakes // Limnology and Oceanography. 1977. - Vol. 22. — № 2.

13. Суторихин И.А., Акулова О.Б., Букатый В.И., Фроленков И.М. Определение трофического статуса пресноводных озер Алтайского края в период 2013-2016 гг. по гидрооптическим характеристикам // Известия АлтГУ. 2017. — № 1 (93). DOI:10.14258/izvasu(2017)1-10.

14. Акулова О.Б., Букатый В.И., Попов К.П. Содержание растворенного органического вещества в водоемах разного трофического уровня // Вестник АГАУ. - 2017. № 3 (149). 